\title{
PENERAPAN SISTEM INFORMASI PEMASARAN \\ PADA USAHA KECIL MENENGAH (UKM) DI PURWOKERTO
}

\author{
Arini Hidayah \\ Universitas Muhammadiyah Purwokerto \\ Purnadi \\ Universitas Muhammadiyah Purwokerto
}

\begin{abstract}
This research, entitled "Implementation of Information Systems Marketing On Small and Medium Enterprises (SMEs) in Purwokerto". The purpose of this study was to determine the profile and the problems faced by SMEs in Purwokerto, and to investigate the role of local governments to SMEs in Purwokerto. The object of this study is the Small and Medium Enterprises in Purwokerto. Results from this study is an integrated website on SMEs in Purwokerto which contains information about the product, the company's distribution network, promotional activities and direct sales company and product prices firm
\end{abstract}

Keywords: Marketing, SME, Marketing and Information Systems Marketing

\section{ABSTRAK}

Penelitian ini berjudul "Penerapan Sistem Informasi Pemasaran Pada Usaha Kecil Menengah (UKM) Di Purwokerto". Tujuan penelitian ini adalah untuk mengetahui profil dan permasalahan yang dihadapi oleh UKM di Purwokerto, serta untuk mengetahui peran pemerintah daerah terhadap UKM yang ada di Purwokerto. Objek penelitian ini adalah Usaha Kecil dan Menengah yang ada di Purwokerto. Hasil dari penelitian ini adalah sebuah website terpadu tentang UKM di Purwokerto yang berisi tentang informasi produk, jaringan distribusi perusahaan, kegiatan promosi dan penjualan langsung perusahaan dan harga produk perusahaan

Kata Kunci : Pemasaran, UKM, Sistem Pemasaran dan Informasi Pemasaran

\section{PENDAHULUAN}

\section{A. Latar Belakang}

Pada umumnya permasalahan yang dihadapi oleh usaha kecil berkaitan dengan masalah kemampuan manajemen atau pengelolaan yang kurang profesional. Hal ini disebabkan pengetahuan yang dimiliki sangat terbatas. Masalah-masalah manajemen ini meliputi, masalah struktur permodalan, personalia dan pemasaran.

Selain masalah di atas, ada juga masalah teknis yang sering dijumpai yaitu : masalah belum dimilikinya sistem administrasi keuangan dan manajemen yang baik, karena belum dipisahkannya kepemilikan dan pengelolaan perusahaan dengan keluarga, masalah bagaimana menyusun proposal dan membuat studi kelayakan untuk memperoleh pinjaman 
baik dari Bank maupun modal ventura, karena kebanyakan usaha kecil mengeluh berbelitnya prosedur mendapatkan kredit, masalah menyusun perencanaan bisnis karena persaingan dalam merebut pasar semakin ketat, masalah akses terhadap teknologi terutama bila pasar dikuasai oleh perusahaan/grup bisnis tertentu dan selera konsumen cepat berubah, masalah memperoleh bahan baku terutama karena adanya persaingan yang ketat dalam mendapatkan bahan baku, bahan baku berkualitas rendah, dan tingginya harga bahan baku, masalah inovasi dan perbaikan kualitas barang dan efisiensi.

Pemerintah Indonesia melalui berbagai kebijakan ekonomi telah berusaha mengembangkan dan memberdayakan usaha kecil dan menengah sebagai penopang bagi perekonomian nasional, baik sebagai penyedia lapangan kerja, lapangan usaha maupun penghasil devisa negara. Hal ini dapat dilihat dari data BPS tahun 2000 yang menyebutkan bahwa Sektor Koperasi dan UKM mampu menyerap tenaga kerja secara nasional sebesar 99,47\%. Dalam pembentukan Produk Domestik Bruto (PDB), sektor Koperasi dan UKM memberikan kontribusi sebesar 41,32\% dan 16,38\%.

Dalam kegiatan usaha, sektor UKM dan Koperasi memberikan kontribusi sebesar 99\% dari total unit usaha. Sektor UKM dan Koperasi tumbuh sebesar $276 \%$ dalam kegiatan ekspor nasional.

Suatu sistem informasi pemasaran (SIP) terdiri dari orang-orang, peralatan, dan prosedur-prosedur untuk mengumpulkan, menyortir, menganalisis, mengevaluasi dan mendistribusikan informasi yang tepat waktu, akurat, dan dibutuhkan kepada pembuat keputusan pemasaran (Kotler, 1995; 143). Pengembangan sistem informasi berarti menyusun suatu sistem yang baru untuk mengganti sistem yang lama atau memodifikasi sistem yang sudah ada. Aktivitas untuk memodifikasi atau bahkan pembuatan sistem informasi baru mensyaratkan keterlibatan pihak pemakai dan pihak manajemen.

\section{B. Perumusan Masalah}

Dari latar belakang di maka permasalahan yang akan dikaji dalam penelitian ini adalah :

1. Bagaimanakah profil UKM yang ada di Purwokerto dilihat dari sistem informasi pemasaran yang digunakan?

2. Permasalahan dan kendala apakah yang dihadapi UKM di Purwokerto dalam penerapan sistem informasi pemasaran?

3. Sejauh manakah peran pemerintah daerah mengembangkan UKM di Purwokerto ?

4. Upaya apa yang dapat dilakukan untuk mengembangkan kemampuan pengembangan sistem informasi pemasaran bagi UKM di Purwokerto ?

\section{TUJUAN DAN MANFAAT}

\section{A. Tujuan Penelitian}

1. Untuk mengetahui profil UKM yang ada di Purwokerto dilihat dari sistem informasi pemasaran yang digunakan 
2. Untuk mengetahui permasalahan dan kendala yang dihadapi UKM di Purwokerto dalam penerapan sistem informasi pemasaran.

3. Untuk mengetahui sejauh manakah peran pemerintah daerah mengembangkan UKM di Purwokerto

4. Untuk mengetahui upaya yang dapat dilakukan untuk mengembangkan kemampuan pengembangan sistem informasi pemasalahan bagi UKM di Purwokerto.

\section{B. Manfaat Penelitian}

Diharapkan dari hasil penelitian ini dapat memberikan kontribusi dalam usaha pemecahan masalah-masalah pembangunan, khususnya bagi Pemerintah Daerah. Sehingga dapat dipakai

sebagai acuan dan masukan dalam membuat kebijakan berkaitan dengan pembinaan UKM. Bagi para pengusaha yang termasuk UKM, penelitian ini diharapkan dapat memberikan kontribusi bagi UKM dalam membuat sistem informasi pemasaran yang baik sesuai dengan kondisi UKM tersebut. Sehingga UKM mampu memperbaiki produk dan memberikan kontribusi bagi perekonomian di Purwokerto.

\section{TINJAUAN PUSTAKA}

\section{a. Pengertian dan Karakteristik Usaha Kecil}

Pengertian usaha kecil di Indonesia masih sangat beragam. Menurut Departemen Perindustrian dan Bank Indonesia (1990) mendefinisikan usaha kecil berdasarkan nilai asetnya, yaitu suatu usaha yang asetnya (tidak termasuk tanah dan bangunan) bernilai kurang dari Rp.600 Juta. Sedangkan departemen Perdagangan mendefinisikan usaha kecil sebagai usaha yang modal kerjanya kurang dari Rp. 25 Juta. Menurut Badan Pusat Statistik (BPS), industri kecil adalah usaha industri yang melibatkan tenaga kerja antara 5 sampai dengan 19 orang. Sedangkan industri rumah tangga adalah usaha industri yang mempekerjakan kurang dari 5 orang.

Sedangkan menurut Undang-undang Nomor 9 tahun 1995, yang dimaksud dengan usaha kecil adalah :

1. Memiliki kekayaan bersih paling banyak Rp.200 Juta, tidak termasuk tanah dan bangunan tempat usaha, atau

2. Memiliki hasil penjualan tahunan paling banyak Rp. I Miliar

3. Milik Warga Negara Indonesia,

4. Berdiri sendiri, bukan merupakan anak perusahaan atau cabang perusahaan yang dimiliki, dikuasai atau berafiliasi baik langsung maupun tak langsung dengan usaha menengah dan besar,

5. Berbentuk usaha orang perorangan, badan usaha yang tidak berbadan hukum, atau badan usaha berbadan hukum, termasuk koperasi. 
Dari berbagai definisi diatas dapat disimpulkan bahwa usaha kecil adalah suatu usaha yang bercirikan:

1. kegiatan usahanya tidak formal serta mempunyai struktur organisasi yang sederhana

2. jumlah tenaga kerja terbatas, berkisar antara 2 sampai dengan 25 orang

3. manajemen dan sistem pencatatannya sangat sederhana

4. skala ekonomi kecil dan daerah pemasarannya terbatas

b. Sistem Informasi Pemasaran

Menurut Kotler (2012), sistem informasi pemasaran terdiri dari orang, peralatan, dan prosedur untuk mengumpulkan, mensortir, menganalisis, mengevaluasi dan mendistribusikan informasi yang diperlukan, tepat waktu, dan akurat untuk pembuat keputusan pemasaran. Sedangkan fungsi sistem informasi pemasaran adalah :

a. Menilai Kebutuhan Informasi.

b. Mengembangkan Informasi yang Diperlukan.

c. Mendistribusikan Informasi.

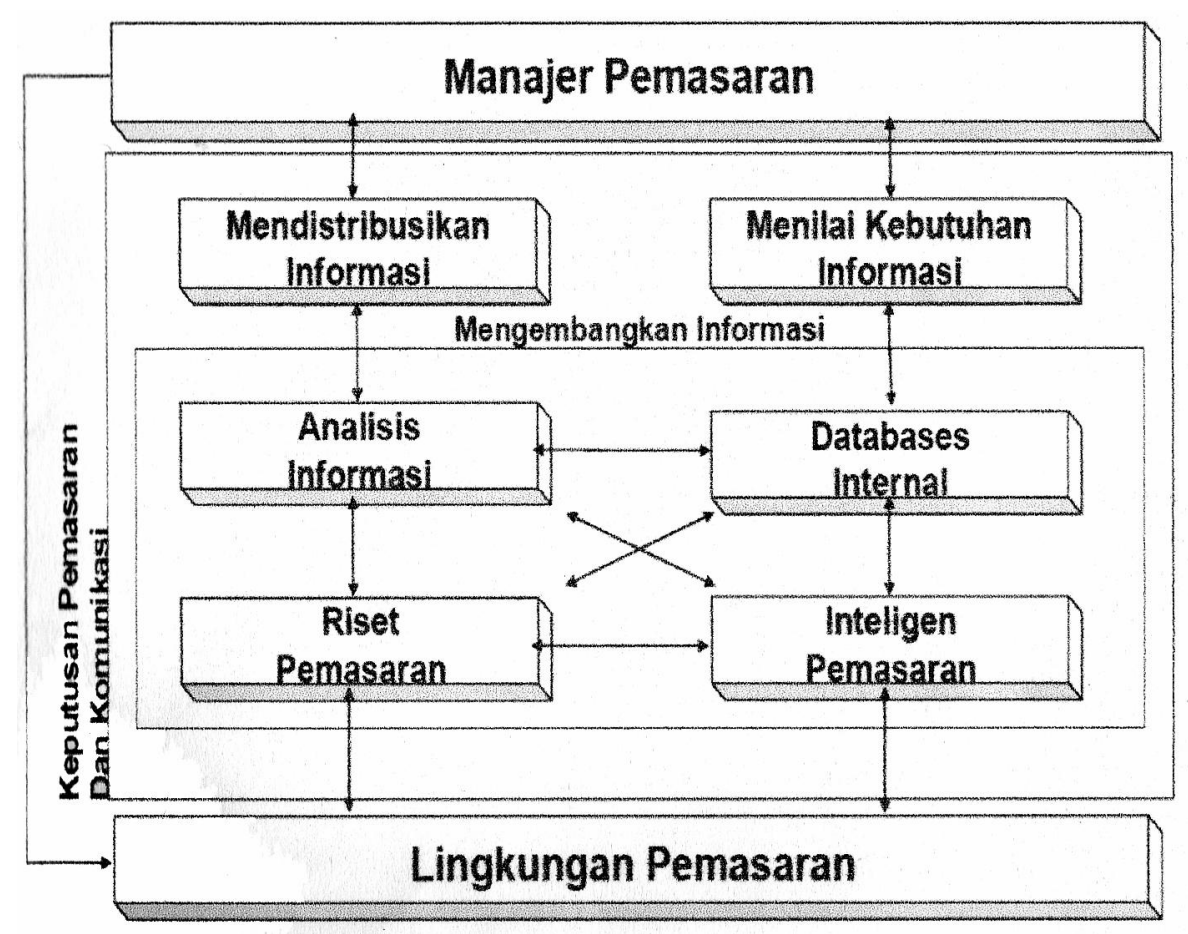

\section{METODE PENELITIAN}
A. Lokasi Penelitian
Penelitian dilakukan pada UKM khususnya yang ada di Purwokerto.
B. Jenis Penelitian 
Jenis penelitian yang digunakan adalah penelitian deskriptif, yaitu penelitian yang bertujuan untuk mencari gambaran tentang karakteristik populasi yang diteliti.

\section{Teknik Pengumpulan Data}

Data primer maupun data sekunder diperoleh dengan cara melakukan wawancara dan survey di lapangan.

\section{Populasi dan Sampel}

Populasi dalam penelitian ini meliputi seluruh pelaku UKM yang ada di Purwokerto. Sedangkan jumlah sampel yang akan dijadikan profil sebanyak 20 buah

\section{E. Metode Sampling}

Untuk mengambil sampel sebagai nara sumber akan digunakan metode purposive sampling. Sampel diambil berdasarkan karakteristik perusahaan yaitu perusahaan yang banyak menyerap tenaga kerja.

\section{F. Metode Analisis Data}

Metode Analisis Data dengan menggunakan data yang di dapat dari perusahaan dan memilih data yang boleh diinformasikan untuk menjelaskan gambaran secara umum tentang profil UKM di Purwokerto

\section{HASIL DAN PEMBAHASAN}

Penelitian ini akan meneliti tentang pentingnya penerapan Sistem Informasi Pemasaran bagi Usaha Kecil Menengah di Purwokerto. Variabel-variabel dalam penelitian ini yaitu subsistem produk, subsistem tempat, subsistem promosi dan subsistem harga. Pengambilan sampel dilakukan dengan metode purposive sampling yaitu UKM yang menyerap banyak tenaga kerja. Berdasarkan kriteria tersebut jumlah usaha kecil menengah yang akan dijadikan profil sebanyak 20 buah.

Berdasarkan hak tersebut maka diperoleh data seperti tercantum pada tabel V.1 di bawah :

Tabel 1. Data UKM

\begin{tabular}{|l|l|l|}
\hline No & Bidang Usaha & Jumlah \\
\hline 1. & Kuliner & 17 \\
\hline 2. & Non Kuliner & 3 \\
\hline & Jumlah & 20 \\
\hline
\end{tabular}

Berdasarkan hasil wawancara dan jawaban kuesioner maka jawaban responden dapat menggambarkan profil UKM secara umum di Purwokerto yaitu sebagai berikut :

1. Subsistem Produk:

a. Produk yang ditawarkan memiliki ciri khas

b. Produk yang ditawarkan tidak mengikuti trend mode yang sedang berlangsung pada saat ini

c. Tidak terdapat produk baru

d. Produk yang ditawarkan bervariasi 
e. Bahan baku yang digunakan untuk membuat produk aman, sehat, halal dan bersih

f. Produk tidak mudah rusak

2. Susistem tempat : tempat penjualan produk terdiri dari
a. Toko khusus
b. Pasar tradisional

3. Subsistem Promosi :

a. Belum dilakukan promosi melalui surat kabar atau majalah

b. Promosi dilakukan melalui pameran-pameran yang difasilitasi pemerintah daerah

c. Belum dilakukan promosi melalui media internet

d. Tidak terdapat hotline untuk menyalurkan keluhan

e. Tidak mempunyai sales promotion

4.Subsistem harga : harga yang ditawarkan sangat penting bagi perusahaan karena terdapat banyak pesaing dalam industri yang sama

Berdasarkan hasil penelitian maka permasalahan dan kendala yang dihadapi UKM di Purwokerto dalam penerapan Sistem Informasi Pemasaran adalah belum adanya kegiatan promosi secara terpadu yang menggambarkan profil UKM tersebut.

Hal tersebut dikarenakan UKM tidak mempunyai data dan dokumentasi untuk melakukan kegiatan promosi terpadu.

Kendala lain banyak UKM yang merasa tidak perlu melakukan kegiatan Sistem Informasi Pemasaran secara terpadu dan mengandalkan kegiatan promosi secara tradisional

Peran Pemerintah Daerah dalam mengembangkan UKM di Purwokerto

1. Memfasilitasi Kemitraan dengan Lembaga Keuangan sehingga UKM di Purwokerto lebih bankable

2. Membangun UKM yang berdaya saing tinggi

3. Memperluas pangsa pasar produk domestik

4. Meningkatkan kualitas kelembagaan ukm

Upaya yang dapat dilakukan untuk permasalahan dan kendala tersebut yaitu dengan membuat sebuah website (blog) terpadu untuk menggambarkan UKM yang ada di Purwokerto.

Langkah-langkah yang dilakukan yaitu :

a. Analysis : melakukan pengumpulan data dari UKM

b. Design : melakukan pemilihan peralatan, merinci program, dan membuat desing

c. Coding : melakukan pembangunan sistem

d. Testing : Uji coba sistem dan pengisian sistem

e. Maintenance : kegiatan ini dilakukan apabila sistem telah diterapkan sepenuhnya, untuk menguji keefektifan dari sistem 


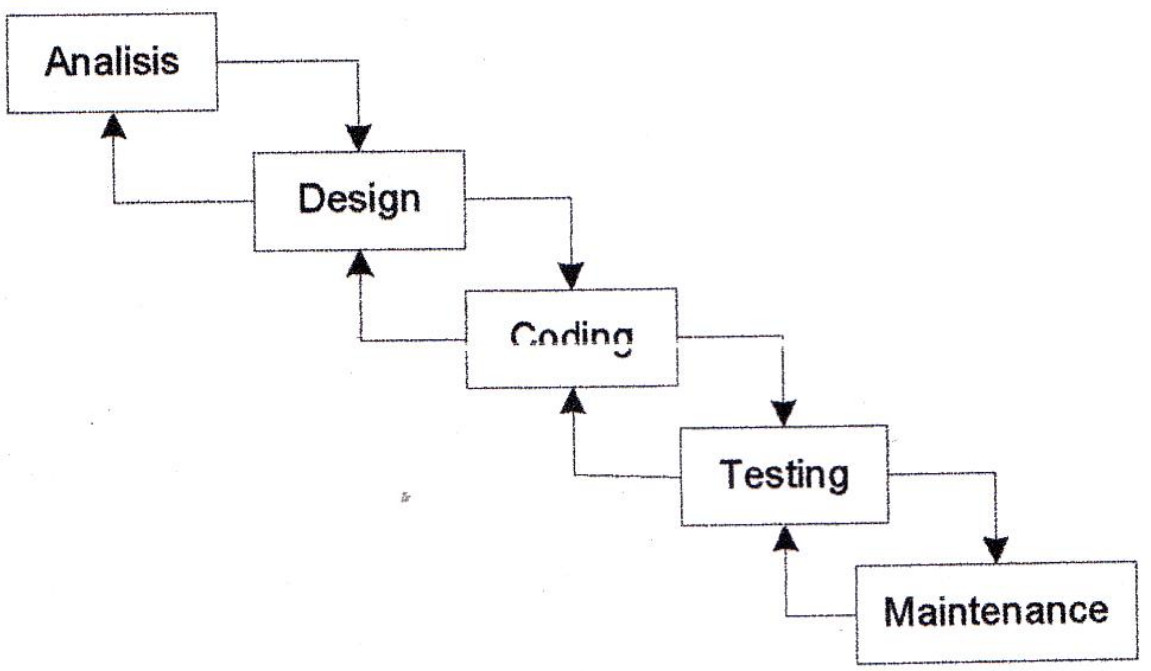

\section{KESIMPULAN DAN SARAN}

\section{A. KESIMPULAN}

1. Profil UKM di Purwokerto sebagai berikut produk UKM sudah mempunyai ciri khas hanya tidak terdapat variasi hal ini dikarenakan karena UKM sebagian besar bergerak di bidang kuliner

2. Kendala dalam penerapan Sistem Informasi Pemasaran tidak ada data dan dokumentasi terpadu dari UMK tersebut

3. Peran Pemerintah Daerah sangat besar di dalam mengembangkan UKM di Purwokerto

4. Adanya pembuatan blog tentang profil UKM di Purwokerto

\section{B. KETERBATASAN DAN SARAN}

1. Beberapa UKM tidak mau memberikan data-datanya terkait persaingan

2. UKM perlu meningkatkan inovasi produknya sehingga lebih mampu bersaing dan pasarnya lebih luas

3. Perlu dukungan dari pemerintah terutama di bidang permodalan

4. Pengembangan lebih lanjut dari blog UKM terpadu

\section{DAFTAR PUSTAKA}

Acim Supriadi. 2014. Menjadi Wiraswasta, Mengapa Tidak?. Jurnal Pengembangan Wiraswasta. Volume 5 Nomor 02, Januari 2014.STIE Ipwija. Jakarta.

Arman Hakim dkk, 2014. Membangun Spirit Enterpreneur Muda; Suatu Pendekatan Praktis. Penerbit PT ElexKomputindo, Jakarta.

Deborah V. Brazeal dan Theodore T. 2009. The Genesis of Entrepreneurship. Entrepreneurship Theory and Practice, Baylor University, Vol.23 p. 319-334.

Dermawan W. 2000. Riset Bisnis. Edisi Pertama. Penerbit BPFE Jogjakarta.

Fandy Tjiptono, 2010. Strategi Pemasaran, Edisi Ketiga, Penerbit ANDI, Yogyakarta. 
Freddy Rangkuti, 2008. Analisis SWOT Teknik Membedah Kasus Bisnis, Penerbit Gramedia, Jakarta.

Jess H. Chua dkk. 2009. Defining the Family Business by Behavior. Entrepreneur ship Theory and Practice. Baylor University.Vol. 23. No.4

Kotler,2012. Manajemen Pemasaran Analisis Perencanaan Implementasi dan Control, Penerbit Prehalindo, Jakarta.

Philip Kotler, dan Gary Amstrong, 2010. Prinsip-Prinsip Pemasaran, Penerbit Erlangga, Jakarta.

Swastha. Basu dan Irawan, 2002, Manajemen Pemasaran Modern, Penerbit Liberty, Yogyakarta.

Syahputra, 2012. Merekonstruksi Ulang UKM Dalam Pemulihan Ekonomi.Makalah disampaikan dalam Lokakarya UKM sebagai Core Konsep Penopang Perekonomian Indonesia.dl UMM.

Warren J. Keegan. 2002. Manajemen Pemasaran Global, Edisi V, Penerbit Prehalindo, Jakarta.

William D. Bygrave. 2002. The Portable MBA Entepreneurship (Terjemahan). Binarupa Aksara. Jakarta.

William F. Glueck dan Lawrence R. Jauch, 2000. Manajemen Strategis dan Kebijakan Perusahaan, Penerbit Erlangga, Yogyakarta.

Undang-undang Republik Indonesia Nomor 9 Tahun 1995 tentang Usaha Kecil. 